\title{
Unusual case of appendicitis
}

\author{
Luke Nelson Allen, ${ }^{1,2}$ Alice Yi-Chien Tsai ${ }^{3}$
}

${ }^{1}$ Nuffield Department of Population Health, University of Oxford, Oxford, UK

${ }^{2}$ Department of Public Health, Royal Cornwall Hospital, Truro, UK

${ }^{3}$ Imperial College London, London, UK

\section{Correspondence to} Dr Luke Allen, drlukeallen@gmail.com

Accepted 12 May 2016

\section{SUMMARY}

A teenage girl was admitted to the paediatric assessment unit with non-specific abdominal pain that gradually localised to the right iliac fossa (RIF). She remained systemically well; investigations including blood tests, urine sample and abdominal ultrasound were inconclusive. Surgical opinion was sought and the decision was made to perform a diagnostic laparoscopy due to the ongoing pain. Laparoscopy showed no evidence of any significant pathology, and appendicectomy was performed following the routine practice. Numerous pinworms came out while the appendix was resected. The RIF pain resolved and the patient made a full post-operative recovery. A stat dose of mebendazole and amoxicillin were given and the immediate family was also treated. Enterobius vermicularis (pinworm) causes significant morbidity worldwide and has a high prevalence among children in the UK. It can be easily treated and prompt recognition based on clinical symptoms can potentially prevent unnecessary surgery.

\section{BACKGROUND}

Non-specific abdominal pain is a common clinical presentation in teenage girls and this demographic group receives more unnecessary operations than boys and younger girls.

Enterobius vermicularis (pinworm) is a relatively common parasite and infection can result in abdominal pain. Burkhart and Burkhart ${ }^{2}$ estimate that up to $50 \%$ of British children may be infected with E. vermicularis; however, it is rarely considered as a differential diagnosis of non-specific abdominal pain.

The present study presents a classic case of parasitic appendicitis in a teenage girl and discusses the clinical features, treatment and global burden of disease.

\section{CASE PRESENTATION}

A 15-year-old Caucasian girl was admitted to the paediatric department with a 24-hour history of abdominal pain which gradually localised to the right iliac fossa (RIF), accompanied by nausea but without vomiting. She had no change in bowel habits and no urinary symptoms.

The patient was otherwise well with no significant medical history, no previous hospital admissions and no surgical history.

She did not take any regular medications and did not have any known allergies. Menarche was at age 11 years and the patient had had regular menstruation with no gynaecological problems.

On examination, there was moderate tenderness on deep palpation of the RIF and the physiological parameters including heart rate, respiratory rate, temperature and blood pressure were all within normal limits.

\section{INVESTIGATIONS}

1. $C$ reactive protein was $<0.1$

2. Urea and electrolytes and glucose: all within normal limits.

3. Liver function tests: all within normal limits.

4. Full blood count: haemoglobin and white cells were all within normal limits. The eosinophils count was marginally raised at $1.01 \times 10^{9} / \mathrm{L}$ constituting $11.6 \%$ of white cells.

5. Mid-stream urine dipstick: no abnormalities detected.

6. Urine flow cytometry was negative and culture was not performed.

7. Transcutaneous abdominal ultrasound did not reveal signs of any pathology.

\section{DIFFERENTIAL DIAGNOSIS}

Since appendicitis is common and potentially lifethreatening, it was at the top of our differential list. Despite encouraging blood results, we felt we could not rule it out. Non-specific abdominal pain could also be due to irritable bowel syndrome; however, there was no bloating, change in bowel habit or obvious psychological stressors at home. Urinary tract infections can cause similar symptoms, but there was no frequency or dysuria and the urinary investigations ruled out this differential. The patient reported no gynaecological symptoms and she was not in the right stage of her cycle for mittelschmerz (mid-cycle pain) to be a likely cause. Other differentials for abdominal pain, including inflammatory bowel syndrome, Meckel's diverticulum and ovarian cysts, were not supported by the history, examination and investigation findings.

The patient was systemically stable; however, the pain persisted, requiring regular analgesics. The paediatric team admitted her and requested a surgical review to rule out appendicitis.

\section{OUTCOME AND FOLLOW-UP}

A surgical opinion was sought to rule out appendicitis. Owing to the persisting abdominal pain, the decision was made to perform a diagnostic laparoscopy. The laparoscopy showed no significant pathology in the ovaries, uterus and small bowel; the appearance of the appendix was lily white. Appendicectomy was performed following the routine practice in the situation of no explanation for RIF pain. While resecting the appendix from the base, a multitude of worms came out of the diving point (video 1). The appendix was swiftly removed using an endoscopic retrieval pouch. Stray 


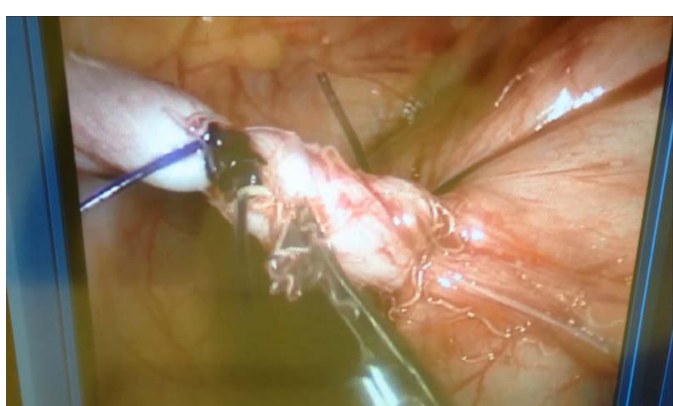

Video 1 Laparotomy findings.

worms that emerged as the appendix was divided were removed with the suction irrigator. This approach cleared all of the worms that had escaped into the peritoneum and we recommend this approach to others in a similar situation.

Histology confirmed both the absence of acute appendicitis and the presence of E. vermicularis.

The patient made a full recovery and the abdominal pain resolved. E vermicularis can be treated with piperzanine or mebendazole. The British National Formulary recommends a stat dose of $100 \mathrm{mg}$ mebendazole for the patient and family (who may also be carrying the helminth). Since this drug does not kill the eggs, a second dose is required 2 weeks later. The cure rate is estimated to be around $90 \%$ and confirmation of eradication is purely based on the absence of symptoms (chiefly pruritus ani). The patient and family were treated in line with this guidance and the patient was discharged after 48 hours with simple analgesics. The infection did not recur and none of the family members reported symptoms.

\section{DISCUSSION}

Abdominal pain is common in children (under 18 years) with a strong female preponderance in those aged over 8 years. Of those presenting with acute abdominal pain requiring inpatient assessment, only $25 \%$ have acute appendicitis. ${ }^{1}$

According to the Global Burden of Disease project, parasitic worms were the leading contributor to the 26 million disability adjusted life years attributed to neglected tropical diseases in 2010, and are one of the most common human infections worldwide. Global estimates of prevalence in children range from $61 \%$ in India to $29 \%$ in Denmark. The prevalence in British children may be as high as $50 \% .^{2}$

Enterobius infection is asymptomatic in the majority of patients. Our patient denied nocturnal pruritus ani, which is the most common presenting symptom; however, infestation can also present with ileocolitis, enterocutaneous fistula, urinary tract infection, mesenteric abscesses and salpingitis. ${ }^{3}$ Diagnosis is based on early morning application of sellotape or a clear swab to the anus with microscopy to inspect for eggs (figure 1). While eosinophilia can occur, it is only generally seen with invasion into the peritoneal cavity.

Enterobius infestation is often found in patients with symptoms of appendicitis, and the global prevalence of co-occurrence may be as high as $41.8 \%$. Enterobius can cause a hypersensitivity tissue reaction and has been reported to obstruct the appendix lumen. However, these findings are uncommon and the majority of patients have a non-inflamed appendix at surgery. ${ }^{4}$

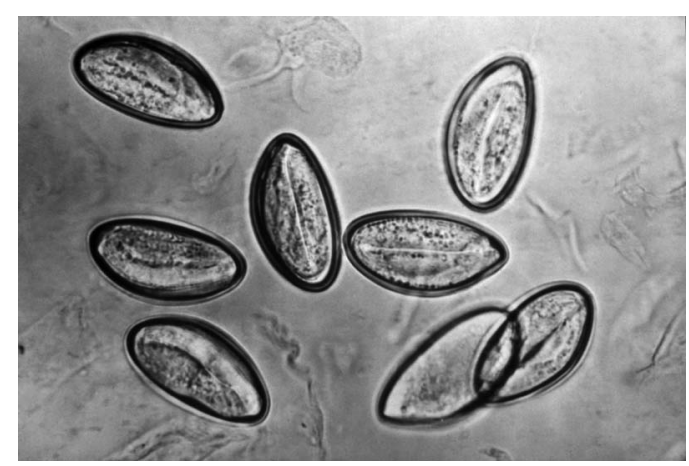

Figure 1 Eggs seen under light microscopy (creative commons licence).

The patient in this case had a non-inflamed appendix and it is still unclear whether the pinworm infection was the source of the RIF pain. If the patient had reported pruritus ani, a dose of mebendazole would have had diagnostic and therapeutic value.

\section{Learning points}

- Helminth infection is a significant cause of disability adjusted life years worldwide.

- While nematode infections are more common in hot and humid regions with poor sanitation, the prevalence of Enterobius vermicularis infection in British children may be as high as $50 \%$.

- Pruritus ani is the most common presenting symptom and diagnosis relies on obtaining perianal eggs for microscopy.

- E. vermicularis can cause right iliac fossa pain.

- The infection is easily treated and prompt recognition based on clinical symptoms can prevent unnecessary surgery.

Acknowledgements The authors wish to thank the teams at the Royal Cornwall Hospital involved in this case.

Contributors LNA wrote the initial drafts. AY-CT provided the video file. Both authors were involved in the case, planned the manuscript and reviewed the final draft.

Competing interests None declared.

\section{Patient consent Obtained.}

Provenance and peer review Not commissioned; externally peer reviewed.

\section{REFERENCES}

1 Buddingh $\mathrm{KT}$, Wieselmann $\mathrm{E}$, Heineman $\mathrm{E}$, et al. Constipation and nonspecific abdominal pain in teenage girls referred for emergency surgical consultation. J Pediatr Gastroenterol Nutr 2012;54:672-6.

2 Burkhart CN, Burkhart CG. Assessment of frequency, transmission, and genitourinary complications of enterobiasis (pinworms). Int I Dermatol 2005;44:837-40.

3 Shoup B. Diagnosis and management of pinworm infection. Primary Care Update for Ob/Gyns 2001:8:240-3.

4 Yildirim S, Nursal TZ, Tarim A, et al. A rare cause of acute appendicitis: parasitic infection. Scand I Infect Dis 2005;37:757-9. 
Copyright 2016 BMJ Publishing Group. All rights reserved. For permission to reuse any of this content visit http://group.bmj.com/group/rights-licensing/permissions.

BMJ Case Report Fellows may re-use this article for personal use and teaching without any further permission.

Become a Fellow of BMJ Case Reports today and you can:

- Submit as many cases as you like

- Enjoy fast sympathetic peer review and rapid publication of accepted articles

- Access all the published articles

- Re-use any of the published material for personal use and teaching without further permission

For information on Institutional Fellowships contact consortiasales@bmjgroup.com

Visit casereports.bmj.com for more articles like this and to become a Fellow 